\title{
Effects of Inorganic Anions on the Activation of Acid Sialidases
}

\author{
Megumi Nagaoka, ${ }^{a}$ Takayuki Shiraishi, ${ }^{a}$ Kimio Furuhata, ${ }^{b}$ and Yutaka UdA ${ }^{*, a}$ \\ ${ }^{a}$ Laboratory of Health Chemistry, Faculty of Pharmaceutical Science, Niigata University of Pharmacy and Applied Life \\ Sciences; 5-13-2 Kamishin'ei-cho, Nigata 950-2081, Japan: and ${ }^{b}$ Department of Pharmaceutical Chemistry, School of \\ Pharmaceutical Science, Kitazato University; 5-9-1 Minato-ku, Tokyo 108-0072, Japan. \\ Received October 9, 2002; accepted December 24, 2002
}

\begin{abstract}
An acid sialidase partially purified from porcine liver was activated by incubation at $37^{\circ} \mathrm{C}$ under acidic $\mathrm{pH}$. This activation was dependent on $\mathrm{pH}$, time and temperature, but not inhibited by amastatin, an inhibitor of aminopeptidase $A$, in contrast to the case of human placental sialidase. The effects of inorganic anions on the two sialidases from porcine liver and from human placenta were investigated. Among the anions tested, halide ions, especially chloride and bromide ions, markedly enhanced the activation of the two sialidases. However, nitrate, sulfate, sulfite and pyrosulfite ions rarely affected the activation of sialidase from porcine liver, while all of them enhanced the activation of human placental sialidase. The activation of the enzyme from porcine liver was depressed at concentrations of greater than $100 \mathrm{~mm}$ of sodium chloride, whereas the enzyme from human placenta was held at maximum activation until $1 \mathrm{~m}$ sodium chloride. These results suggest the possibility of the participation of enzyme functions different from that of human placental sialidase in the activation process of sialidase.
\end{abstract}

Key words sialidase; neuraminidase; inorganic anion effect

Sialidase [Neuraminidase E.C. 3.2.1.18], which catalyzes the hydrolysis of the terminal sialic acid residues from oligosaccharides, glycoproteins, and glycolipids is widely distributed among living organisms and participates in the metabolism of sialoglycoconjugates. ${ }^{1,2}$ The physiological significance of sialidase was revealed from studies of the pathology of lysosomal sialidase deficiency disease such as isolated sialidase deficiency and galactosialidosis which is a sialidase deficiency combined with partial $\beta$-galactosidase deficiency. $^{3-5)}$ Recent studies on lysosomal sialidase demonstrated that it occurs as a multienzyme complex with $\beta$ galactosidase and carboxypeptidase..$^{6-10)}$ In a previous study, we demonstrated that sialidase purified from human placenta exhibited five protein bands with molecular masses of 78, 64, 46,30 and $20 \mathrm{kDa}$ on sodium dodecyl sulfate-polyacrylamide gel electrophoresis, respectively. ${ }^{11,12)}$ Of these, the $64 \mathrm{kDa}$ protein was identified as an acid $\beta$-galactosidase, the 30 and $20 \mathrm{kDa}$ proteins as the carboxypeptidase component, the $46 \mathrm{kDa}$ protein as $N$-acetyl- $\alpha$-galactosaminidase ${ }^{13)}$ and the $78 \mathrm{kDa}$ protein as immunoglobulin $\mathrm{M} .{ }^{14)}$ Despite the characterization of these proteins, identification of the protein corresponding to sialidase and the relation between sialidase and other components remained unclear.

Although the enzyme has been isolated from various mammalian sources, it remains difficult to purify and characterize lysosomal sialidase because of its lability and membrane-bound character. Verheijen et al. reported that incubation of crude glycoprotein fractions containing sialidase at $37^{\circ} \mathrm{C}$ and acidic $\mathrm{pH}$ results in enhanced and stabilized sialidase activity. ${ }^{6}$ We purified an active sialidase from human placenta by taking advantage of the activation, followed by $p$ aminophenyl thio- $\beta$-galactoside- $\mathrm{CH}-\mathrm{Sepharose}$ affinity chromatography and HPLC on a Shim-pack Diol 300 column. ${ }^{11,12)}$ Later we showed that the activation of sialidase was inhibited by amastatin which is an inhibitor of aminopeptidase $A,{ }^{15)}$ suggesting the participation of protease in the activation of sialidase. Recently, we purified a sialidase from porcine liver. ${ }^{16)}$ The enzyme was also activated by incubation at $37^{\circ} \mathrm{C}$ under acidic $\mathrm{pH}$, as well as the case of human pla- cental sialidase. The activation of sialidase from porcine liver, however, was not inhibited by amastatin, and enhanced by inorganic anions. In the present study, we examined the effects of inorganic anions on the activation of sialidases from human placenta and porcine liver.

\section{MATERIALS AND METHODS}

Materials Concanavalin A (Con-A)-Sepharose 4B and CM-Sepharose were purchased from Amersham Biosciences (Piscatway, U.S.A.). $\alpha$-Methyl D-glucoside, E-64 and diisopropyl fluorophosphate (DFP) were from Sigma Chemical (St. Louis, U.S.A.). Amastatin, leupeptin, chymostatin, antipain, leuhistin, diprotin A, phosphoramidon, arphamenine A, actiononin and pepstatin A were all purchased from Peptide Institute (Osaka, Japan), and bestatin and $\alpha_{2}$-macroglobulin were from Roche Diagnostics (Mannheim, Germany). $N$-Tosyl-L-phenylalanyl chloromethyl ketone (TPCK) and phenylmethylsulfonyl fluoride (PMSF) were from Nacarai Tesque (Kyoto, Japan). 4-Methylumbelliferyl- $\alpha$ - $N$-acetylneuraminic acid (4-MU-NeuAc) was synthesized by the method described previously. ${ }^{17)}$ All other chemicals were obtained from commercial sources and were of the highest grade available.

Enzyme Preparation The human placental sialidase was partially purified by procedures including extraction, Con A-Sepharose adsorption, ammonium sulfate precipitation as described previously. ${ }^{11)}$ Finally, the enzyme preparation obtained by ammonium sulfate precipitation was dialyzed against 50 volumes of $20 \mathrm{~mm}$ potassium phosphate buffer ( $\mathrm{pH}$ 5.2). To obtain the enzyme preparation from porcine liver, extraction, ammonium sulfate precipitation and Con A-Sepharose affinity column chromatography were performed by the procedure described previously. ${ }^{16)}$

Enzyme Assay Sialidase activity was measured with 4MU-NeuAc as the substrate by the procedure described previously. ${ }^{11)}$ The enzyme solution $(100 \mu \mathrm{l})$ was added to $100 \mu \mathrm{l}$ of $0.2 \mathrm{~mm} 4-\mathrm{MU}-\mathrm{NeuAc}$ dissolved in $0.2 \mathrm{~m}$ sodium acetate buffer ( $\mathrm{pH}$ 4.2). After incubation for an appropriate time at 
$37^{\circ} \mathrm{C}$, the reaction was terminated by the addition of $1.5 \mathrm{ml}$ of $0.2 \mathrm{~m}$ glycine- $\mathrm{NaOH}$ buffer $(\mathrm{pH} 10.7)$. The amount of 4methylumbelliferone liberated was measured spectrofluorometrically. One unit of enzyme was defined as the amount of enzyme that catalyzed the release of $1 \mathrm{nmol}$ of sialic acid per $\min$.

Activation of Sialidase Enzyme solutions were prepared with $40 \mathrm{~mm}$ acetate buffer ( $\mathrm{pH} 4.8$ ) containing various concentrations of inorganic anions and incubated at $37^{\circ} \mathrm{C}$ for $90 \mathrm{~min}$. After incubation, the enzyme activity was determined as described above.

\section{RESULTS AND DISCUSSION}

In the purification processes of sialidase from porcine liver, we observed that the sialidase activity in the glycoprotein fraction from porcine liver was increased by standing at $4{ }^{\circ} \mathrm{C}$ for a few weeks and also by incubation at $37^{\circ} \mathrm{C}$ for $60 \mathrm{~min}$ under acidic $\mathrm{pH}$. The activation of the enzyme was most effective in the solution of Tris- $\mathrm{HCl}$ buffer $(\mathrm{pH} 5.2)$ among the various buffers tested; sodium acetate, sodium succinate, sodium citrate, potassium phosphate and sodium 2-( $N$-morpholino) ethane sulfonate (MES) buffers (data not shown). In addition, the enzyme was markedly activated by arginine, histidine and lysine hydrochlorides than the other amino acids. In seeking the factor to activate the sialidase, we found that the activation of the enzyme was not brought
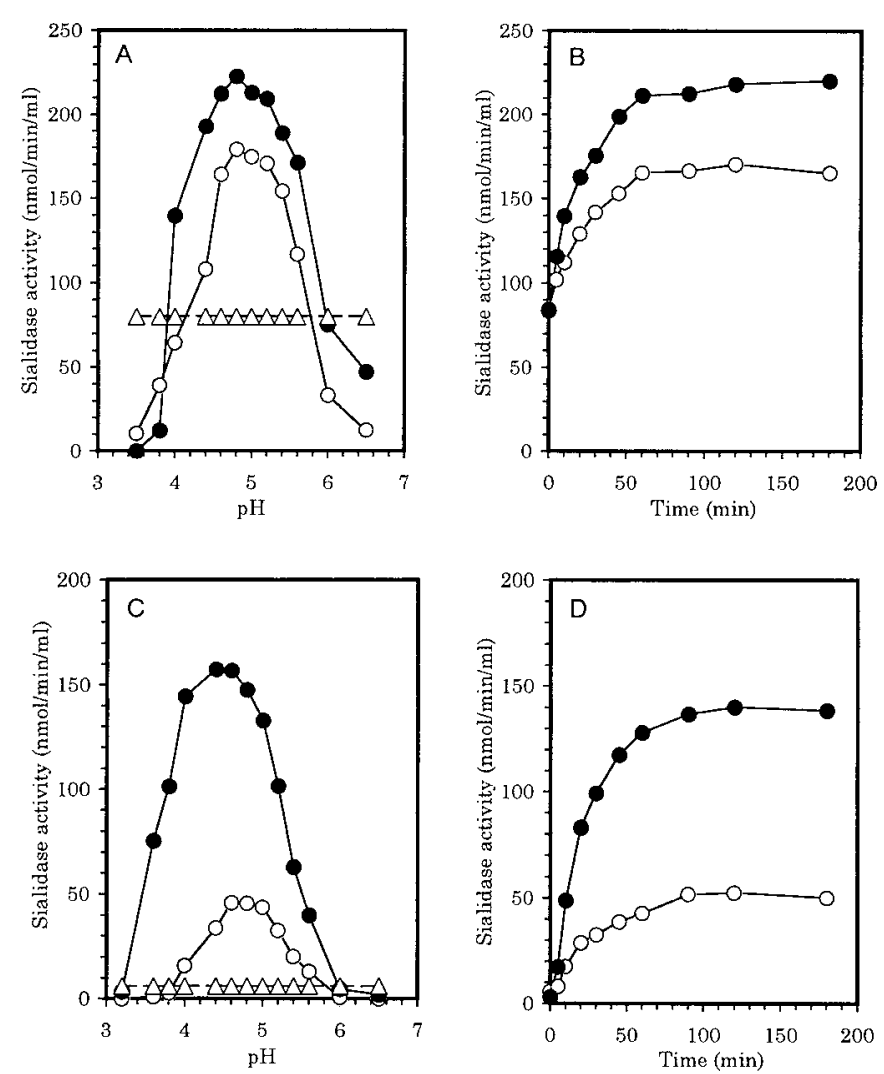

Fig. 1. Effects of $\mathrm{pH}$ and Time on the Activation of Sialidases

The enzyme was placed in $40 \mathrm{~mm}$ sodium acetate buffer ranging in $\mathrm{pH} 3.2$ to 6.6 (A, C) and $\mathrm{pH} 4.8(\mathrm{~B}, \mathrm{D})$ at $37^{\circ} \mathrm{C}$ in the presence $(50 \mathrm{~mm})$ or absence of $\mathrm{NaCl}$ and then the sialidase activity was measured with 4-MU- $N$-acetylneuraminate as a substrate at $\mathrm{pH}$ 4.2. A, B; sialidase from porcine liver, C, D; sialidase from human placenta. 0 , with $\mathrm{NaCl} ; \mathrm{O}$, without $\mathrm{NaCl} ; \triangle$, control (no incubation before measuring enzyme activity). Data are mean values from three determinations. about by tris(hydroxymethyl)-aminomethane or basic amino acids but by chloride ions. The activation of sialidase from porcine liver by chloride ions was not inhibited by amastatin that inhibited the activation of the enzyme from human placenta (data not shown).

To investigate the effect of $\mathrm{pH}$ on the activation of sialidase, the glycoprotein fractions from porcine liver and human placenta were incubated at $37^{\circ} \mathrm{C}$ in $0.05 \mathrm{M}$ sodium acetate buffer with various $\mathrm{pHs}$ in the presence or absence of sodium chloride for $90 \mathrm{~min}$ and the sialidase activities were determined at $\mathrm{pH} 4.2$, respectively. As shown in Figs. 1A and $\mathrm{C}$, the sialidase activities were enhanced only after incubation within the narrow acidic $\mathrm{pH}$ range between 4.4 and 5.5 for porcine liver, and 3.6 and 5.4 for human placenta. Both sialidases were activated in the absence of sodium chloride however, the two enzyme activities were more increased in the presence of sodium chloride. In particular, the activation of the enzyme from human placenta was greatly enhanced in the presence of sodium chloride. The activations of sialidases were also time-dependent in the presence or absence of sodium chloride (Figs. 1B, D).

Figure 2 shows the effects of various anion species on the activation of sialidases from porcine liver and human placenta. Halide ions, especially chloride and bromide ions, increased the enzyme activity in porcine liver. However, nitrite, sulfate, sulfite and pyrosulfite ions, and carbonic anions rarely affected the activation of the enzyme, except citric acid inhibited the activation. Thus, the activation of sialidase from porcine liver was influenced by anionic ion species and was characteristically enhanced by halide ions. In contrast, not only halide ions but also nitrite, sulfate, sulfite, and pyrosulfite ions all activated the sialidase from human placenta.

The effects of the sodium chloride concentration on the activation of the two sialidases were investigated. The enzyme solutions in $40 \mathrm{~mm}$ acetate buffer ( $\mathrm{pH} 4.6)$ containing various concentrations of sodium chloride were allowed to stand at

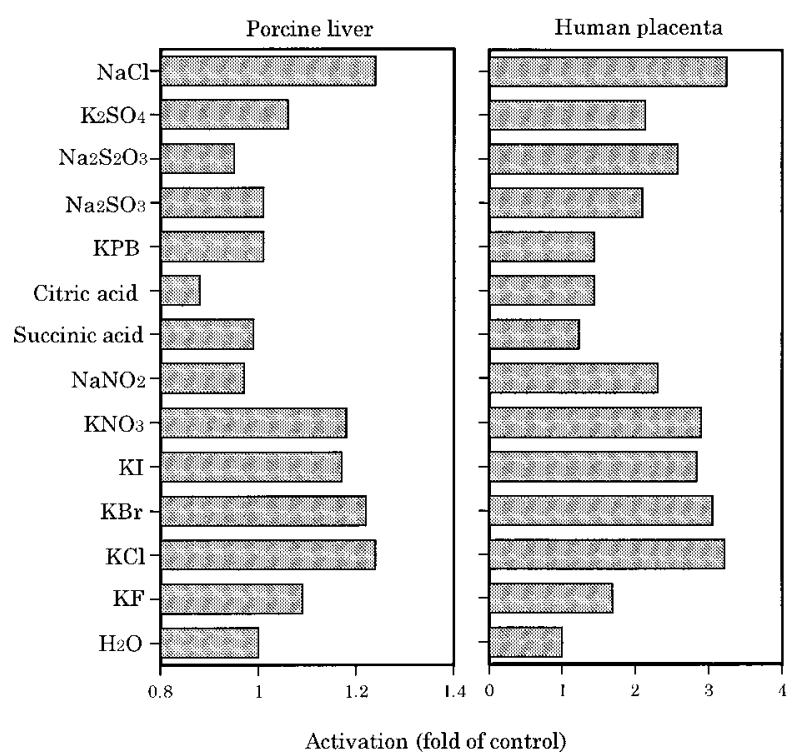

Fig. 2. Effects of Various Anion Species on the Activation of Sialidases

The enzyme was incubated with $40 \mathrm{~mm}$ acetate buffer ( $\mathrm{pH} 4.8$ ) containing $50 \mathrm{~mm}$ solution of each anion at $37^{\circ} \mathrm{C}$ for $90 \mathrm{~min}$, then the sialidase activity was measured with 4-MU- $N$-acetylneuraminate as a substrate at $\mathrm{pH} 4.2$. Data are mean values from three determinations. 

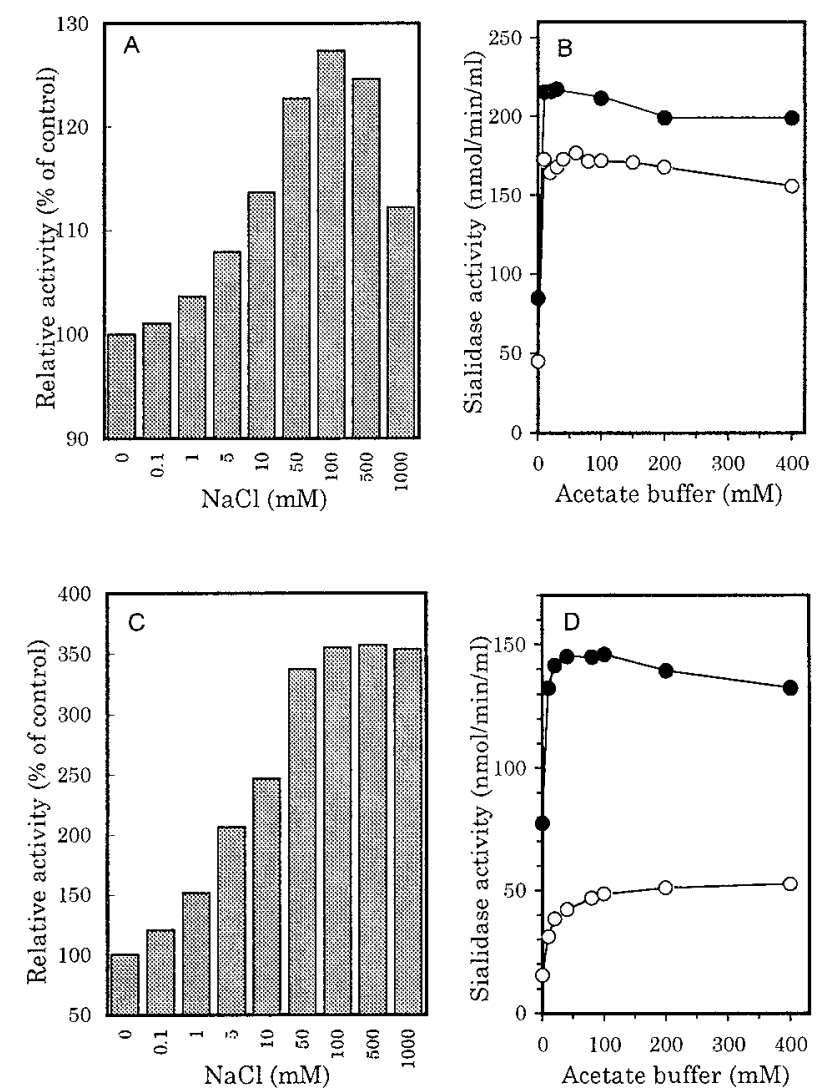

Fig. 3. Effect of the Concentration of $\mathrm{NaCl}$ and Sodium Acetate Buffer on the Activation of Sialidases

The enzyme was placed in $40 \mathrm{~mm}$ sodium acetate buffer ( $\mathrm{pH} 4.8$ ) containing the increasing concentrations of $\mathrm{NaCl}(\mathrm{A}, \mathrm{C})$ and acetate buffer of $\mathrm{pH} 4.8(\mathrm{~B}, \mathrm{D})$ at $37^{\circ} \mathrm{C}$ for $90 \mathrm{~min}$. After incubation, sialidase activity was determined in incubation medium at $\mathrm{pH}$ 4.2. with $\mathrm{NaCl}(50 \mathrm{~mm})$; $\bigcirc$, without $\mathrm{NaCl}$. Data are mean values from three determinations.

$37^{\circ} \mathrm{C}$ for $90 \mathrm{~min}$. After standing, the enzyme activity was determined in the incubation medium at $\mathrm{pH}$ 4.2. As shown in Figs. $3 \mathrm{~A}$ and $\mathrm{C}$, sialidase activities from porcine liver and human placenta were both increased depending upon the concentration of sodium chloride. However, the activation of the enzyme from porcine liver was depressed with sodium chloride concentrations $>100 \mathrm{~mm}$, whereas the enzyme from human placenta was maintained at maximum activation until the sodium chloride concentration reached $1 \mathrm{M}$. These activations by sodium chloride were almost completely consistent with the activation by potassium chloride. To clarify whether the activation of sialidases is influenced by changes in the ionic strength of the medium, the effect of the concentration of acetate buffer on the activation of sialidase was examined. The levels of the activation of sialidases were constant when the acetate buffer concentrations were greater than $10 \mathrm{~mm}$ (Figs. 3B, D). Therefore, the activation of sialidases appears not to be caused by ionic strength.

Of the cation species, sodium, potassium, calcium, magnesium, manganese, and ferrous ions showed no effects on the activation of the two sialidases (Table 1). However, in contrast with the sialidase from porcine liver, the enzyme from human placenta was more strongly inhibited by cuprum and zinc ions.

We previously noted that the sialidase partially purified from human placenta was activated by incubation under
Table 1. Effects of Various Cation Species on the Activation of Sialidases

\begin{tabular}{|c|c|c|c|c|c|}
\hline & \multirow{3}{*}{$(\mathrm{mm})$} & \multicolumn{4}{|c|}{ Relative sialidase activity (\%) } \\
\hline & & \multicolumn{2}{|c|}{ Porcine liver } & \multicolumn{2}{|c|}{ Human placenta } \\
\hline & & $-\mathrm{NaCl}$ & $+\mathrm{NaCl}$ & $-\mathrm{NaCl}$ & $+\mathrm{NaCl}$ \\
\hline Before incubation & & 41.9 & 33.7 & 3.8 & 3.8 \\
\hline \multicolumn{6}{|l|}{ After incubation } \\
\hline Control $\left(\mathrm{K}_{2} \mathrm{SO}_{4}\right)$ & 10 & 100 & 100 & 100 & 100 \\
\hline $\mathrm{MnSO}_{4}$ & 10 & 100 & 97.8 & 100.7 & 91.6 \\
\hline $\mathrm{Ca}(\mathrm{COO})_{2}$ & 10 & 98.6 & 97.8 & 98.2 & 93.8 \\
\hline $\mathrm{CuSO}_{4}$ & 10 & 40.8 & 33.5 & 8.3 & 14.2 \\
\hline $\mathrm{ZnSO}_{4}$ & 10 & 94.6 & 96.8 & 47.2 & 58.7 \\
\hline $\mathrm{MgSO}_{4}$ & 10 & 94.9 & 107.1 & 98.8 & 98.9 \\
\hline EDTA & 10 & 98.6 & 100.6 & 99.4 & 99.5 \\
\hline $\mathrm{CuSO}_{4}$ & 2 & 60.1 & 52.5 & 11.7 & 12.5 \\
\hline $\mathrm{CuSO}_{4}+\mathrm{EDTA}$ & $2+20$ & 101.3 & 95.2 & 100.5 & 97.6 \\
\hline $\mathrm{ZnSO}_{4}^{4}$ & 2 & - & - & 55 & 57.2 \\
\hline $\mathrm{ZnSO}_{4}+\mathrm{EDTA}$ & $2+20$ & - & - & 99 & 98.6 \\
\hline
\end{tabular}

Data are mean values from three determinations.

acidic $\mathrm{pH} .{ }^{11)}$ This activation showed time- and temperaturedependencies and was strongly inhibited by amastatin, a known inhibitor of aminopeptidase A and leucine aminoipeptidase, and zinc ions. ${ }^{15)}$ In addition, we found that the sialidase from porcine liver was activated by incubation at $37^{\circ} \mathrm{C}$ under acidic $\mathrm{pH},{ }^{16)}$ but the activation of the enzyme was not inhibited by amastatin. In the present study, we observed that the activation of sialidase from porcine liver was greatly affected by the $\mathrm{pH}$ and the sialidase activity was enhanced by incubation only within the narrow $\mathrm{pH}$ range between 4.4 and 5.5. The activation of sialidase exhibited not only $\mathrm{pH}$ but also time- and temperature-dependencies. These results suggest the possible involvement of enzyme function in the activation process of sialidase.

The activation of sialidase from porcine liver was not inhibited by amastatin alone but also the other protease inhibitors tested; leupeptin, chymostatin, DFP, TPCK, PMSF, E-64, antipain, leuhistin, diprotin A., phosphoramidon, bestatin, arphamenine $\mathrm{A}, \alpha_{2}$-macroglobulin, and actinonin. Only pepstatin A inhibited the activation of the enzyme (data not shown). These results suggest that the activation of sialidase from porcine liver may be caused by protease that is inhibited by pepstatin A. We are not sure yet whether certain protease is involved in the activation of sialidase or not. Previously, we reported that amastatin strongly inhibited the activation of sialidase from human placenta. The activation of sialidase was affected by halide ions. Some proteases are known to be activated by halide ions. ${ }^{18,19)}$ Halide ions may influence reaction rate of certain protease responsible for the activation of sialidase. However, we recognize that further studies are necessary to clarify the participation of protease on the activation of sialidase.

The activation of sialidase from porcine liver was enhanced by halide anions, especially chloride ions. In contrast, the enzyme from human placenta was enhanced not only by halide ions but also nitrite, sulfate, sulfite, and pyrosulfite ions and the activity was markedly increased compared with that of porcine liver sialidase. The activation of sialidase from porcine liver was affected by the concentration of chloride ions and less affected by cuprum and zinc ions com- 
pared with the enzyme from human placenta. Therefore, the activation of sialidase from porcine liver appears to be brought about by a different enzyme function from that of human placental sialidase.

Recent studies have shown that the mammalian lysosomal sialidase exists as a complex with $\beta$-galactosidase and protective protein..$^{6,20,21)}$ The protective protein possesses carboxypeptidase and amidase activities and is required for multimerization of $\beta$-galactosidase, and expression and stabilization of sialidase activity. ${ }^{22,23)}$ Although the role of protease activity in protective protein is not clear, lack of this protein causes galactosialidosis, a lysosomal storage disease with a combined deficiency of sialidase and $\beta$-galactosidase activities. The relationship between $\beta$-galactosidase multimer and sialidase still remain unclear. Not only protective protein but also some other protease appear to participate in the stabilization and regulation of sialidase activity.

Acknowledgements This work was supported in part by a Grant-in-Aid from the Ministry of Education, Culture, Sports, Science and Technology and from the Promotion and Mutual Aid Corporation for Private School of Japan.

\section{REFERENCES}

1) Schauer R., "Advances in Carbohydrate Chemistry and Biochemistry," Vol. 40, ed. by Tipson R. S., Horton D., Academic Press, New York, 1982, pp. $131-234$.

2) Saito M., Yu R. K., "Biology of the Sialic Acids," ed. by Rosenberg A., PlenumPress, New York and London, 1995, pp. 261-313.

3) Wenger D. A., Tarby T. J., Wharton C., Biochem. Biophys. Res. Commun., 82, 589-595 (1978).

4) Miyatake T., Atsumi T., Obayashi T., Mizuno Y., Ando S., Ariga T.,
Matsui-Nakamura K., Yamada T., Ann. Neurol., 6, 232-244 (1979).

5) Lowden J. A., O’Brien J. S., Am. J. Hum. Genet., 31, 1-18 (1979).

6) Verheijen F. W., Palmeri S., Hoogeveen A. T., Galjaard H., Eur. J. Biochem., 149, 315-321 (1985).

7) Hubbes M., D’Agrosa R. M., Callahan J. W., Biochem. J., 285, 827831 (1992).

8) Potier M., Michaud L., Tranchemontagne J., Thauvette L., Biochem. J., 267, 197-202 (1990).

9) Hiraiwa M., Uda Y., Tsuji S., Miyatake T., Martin B. M., Tayama M., O'Brien J. S., Kishimoto Y., Biochem. Biophys. Res. Commun., 177, 1211-1216 (1991).

10) Hiraiwa M., Saitoh M., Uda Y., Azuma N., Martin B. M., Kishimoto Y., O’Brien J. S., Comp. Biochem. Physiol., 115B, 541-546 (1996).

11) Hiraiwa M., Uda Y., Nishizawa M., Miyatake T., J. Biochem. (Tokyo), 101, 1273-1279 (1987).

12) Hiraiwa M., Nishizawa M., Uda Y., Nakajima T., Miyatake T., J. Biochem. (Tokyo), 103, 86-90 (1988).

13) Tsuji S., Yamauchi T., Hiraiwa M., Isobe T., Okuyama T., Sakimura K., Takahashi Y., Nishizawa M., Uda Y., Miyatake T., Biochem. Biophys. Res. Commun., 163, 1498-1504 (1989).

14) van der Horst G. T. J., Galjart N. J., d'Azzo A., Galjaard H., Verheijen F. W., J. Biol. Chem., 264, 1317-1322 (1989).

15) Hiraiwa M., Yamauchi T., Tsuji S., Nishizawa M., Miyatake T., Oyanagi K., Ikuta F., Uda Y., J. Biochem. (Tokyo), 114, 901-905 (1993).

16) Nagaoka M., Saitoh M., Shiraishi T., Nagaoka H., Iriyama N., Furuhata K., Uda Y., Biol. Pharm. Bull., 21, 682-687 (1998).

17) Furuhata K., Ogura H., Chem. Pharm. Bull., 37, 2037-2040 (1989).

18) Bunning P., Riordan J. F., Biochemistry, 22, 110-116 (1983).

19) Yang J. J., Artis D. R., Van Wart H. E., Biochemistry, 33, 6516-6523 (1994).

20) Verheijen F. W, Brossmer R., Galjaard H., Biochem. Biophys. Res. Commun., 108, 868-875 (1982).

21) Verheijen F. W., Palmeri S., Galjaard H., Eur. J. Biochem., 162, 63-67 (1987).

22) Hoogeveen A. T., Verheijen F. W., Galjaard H., J. Biol. Chem., 258, $12143-12146$ (1983).

23) D’Azzo A., Hoogeveen A. T., Reuser A. J. J., Robinson D., Galjaard H., Proc. Natl. Acad. Sci. U.S.A., 79, 4535-4539 (1982). 